\title{
Managed Aquifer Recharge (MAR) Economics for Wastewater Reuse in Low Population Wadi Communities, Kingdom of Saudi Arabia
}

\author{
Thomas M. Missimer ${ }^{1, *}$, Robert G. Maliva $^{2}$, Noreddine Ghaffour ${ }^{3}$, TorOve Leiknes ${ }^{3}$ \\ and Gary L. Amy ${ }^{3}$
}

1 U.A. Whitaker College of Engineering, Florida Gulf Coast University, 10501 FGCU Boulevard South, Fort Myers, FL 33965-6565, USA

2 Schlumberger Water Services, 1567 Hayley Lane, Suite 202, Fort Myers, FL 33907, USA; E-Mail:rmaliva@slb.com

3 Water Desalination and Reuse Center, King Abdullah University of Science and Technology, Thuwal 23955-6900, Saudi Arabia; E-Mails: noreddine.ghaffour@kaust.edu.sa (N.G.); torove.leiknes@kaust.edu.sa (T.L.); gary.amy@kaust.edu.sa (G.L.A.)

* Author to whom correspondence should be addressed; E-Mail: tmissimer@fgcu.edu; Tel.: +1-239-810-3009.

Received: 3 June 2014; in revised form: 26 July 2014 / Accepted: 29 July 2014 /

Published: 7 August 2014

\begin{abstract}
Depletion of water supplies for potable and irrigation use is a major problem in the rural wadi valleys of Saudi Arabia and other areas of the Middle East and North Africa. An economic analysis of supplying these villages with either desalinated seawater or treated wastewater conveyed via a managed aquifer recharge (MAR) system was conducted. In many cases, there are no local sources of water supply of any quality in the wadi valleys. The cost per cubic meter for supplying desalinated water is $\$ 2-5 / \mathrm{m}^{3}$ plus conveyance cost, and treated wastewater via an MAR system is $\$ 0-0.50 / \mathrm{m}^{3}$ plus conveyance cost. The wastewater reuse, indirect for potable use and direct use for irrigation, can have a zero treatment cost because it is discharged to waste in many locations. In fact, the economic loss caused by the wastewater discharge to the marine environment can be greater than the overall amortized cost to construct an MAR system, including conveyance pipelines and the operational costs of reuse in the rural environment. The MAR and associated reuse system can solve the rural water supply problem in the wadi valleys and reduce the economic losses caused by marine pollution, particularly coral reef destruction.
\end{abstract}


Keywords: managed aquifer recharge; wadi aquifers; desalination; wastewater reuse; water economics; arid lands

\section{Introduction}

Hundreds of small villages and farms exist in wadi (ephemeral streams) valleys throughout the Kingdom of Saudi Arabia (KSA). For centuries, these agrarian communities relied upon shallow groundwater resources to supply potable and irrigation water demands [1]. Anthropogenic impacts, including over-pumping and contamination, have combined to deplete or render unusable the groundwater in shallow alluvial aquifers underlying the wadis [1-3]. Because of the low population density, generally small contribution of crop production to the national economy, and the arid nature of the climate, there are quite limited options available to supply the necessary water to maintain these populations. Nevertheless, rural communities are considered an important part of the cultural heritage of the Kingdom, and finding a solution to their water challenges is a priority. While the KSA is a wealthy country and has technically feasible options to replace the depleted water supplies for these rural communities, such options are even more limited in other, less prosperous countries in the Middle East-North Africa (MENA) region [4].

Four potential methods of providing a comprehensive and reliable water-supply solution are currently being assessed in the KSA. These options include: (1) the construction of seawater reverse osmosis (SWRO) desalination plants and conveyance of this water from the coastline to the end users via pipelines; (2) desalination of brackish groundwater by reverse osmosis (RO), where brackish-water aquifers are available; (3) construction of wadi dams to trap seasonal stormwater discharges and conveyance of the water to the users via pipelines (treated or untreated); and (4) conveyance of treated domestic wastewater to the users via pipeline with subsequent storage and treatment in the underlying aquifer system using aquifer recharge and recovery (ARR) systems. ARR is a form of managed aquifer recharge (MAR) that takes advantage of natural contaminant attenuation processes to improve water quality. ARR systems have an element of treatment along with the conventional storage functions of aquifer storage and recovery (ASR) systems. Use of cistern water capture and other water harvesting methods have been considered, but are insufficiently robust to meet water supply requirements, especially under future global climate change scenarios.

A more detailed analysis of the region shows that the western part of KSA bounding the Red Sea does not contain significant brackish water aquifers that could produce sustainable quantities of water to become a reliable source of water supply. Also, the construction of wadi dams and development of water supplies is based on storm events that have a very uneven frequency and with global climate change, could become more intense and less frequent [5]. Therefore, only two of the four options (seawater desalination and wastewater reuse with ARR) are technically viable as far as potentially providing sustainable water supplies. The feasibility of the two technically viable options depends upon both costs and social acceptance. It should be noted that if all of the supply options were to be found unfeasible, the population living in the small communities and farms would be forced to leave 
their lands and move into densely populated urban areas, therefore exacerbating existing water supply and social issues in the region.

It is the purpose of this paper to assess the relative economics of two potential sustainable water supply options for these small communities and farms; use of seawater desalination versus use of treated domestic wastewater with ARR storage and treatment for both irrigation and indirect use. This assessment is conducted using unit costs for many of the variables, because there is considerable variation in the transport distances from the sea or sources of treated domestic wastewater to water users and corresponding spatial variation in water demands.

\section{Background and Methods}

\subsection{Description of the Rural Wadi Communities and Farms}

Rural communities and small farms are quite common in the wadi valleys of the KSA as well as in many other areas of the MENA region (Figure 1). For centuries, these small communities and farms have been dependent on shallow groundwater for supplies. In the past, there was sufficient recharge to the underlying alluvial aquifer system to maintain the sustainability of the water supply. Aquifer water levels fluctuated seasonally between 1 and $3 \mathrm{~m}$ below surface in the early part of the 1900s, depending upon rainfall accumulation and the occurrences of periodic drought conditions [6]. However, in the modern era, population growth and expansion of agricultural activities has caused depletion of the groundwater resources of wadi alluvial aquifers with water levels commonly dropping 20 to $30 \mathrm{~m}$ below surface in many areas and causing complete aquifer dewatering in some wadi systems [2] (Figure 2).

Figure 1. Large-diameter abandoned well at the center and a dead date palm plantation in western Wadi Qidayd, Saudi Arabia. Aquifer depletion has caused the large-scale failure of small farms and abandonment of some villages as shown by the dead date palms.

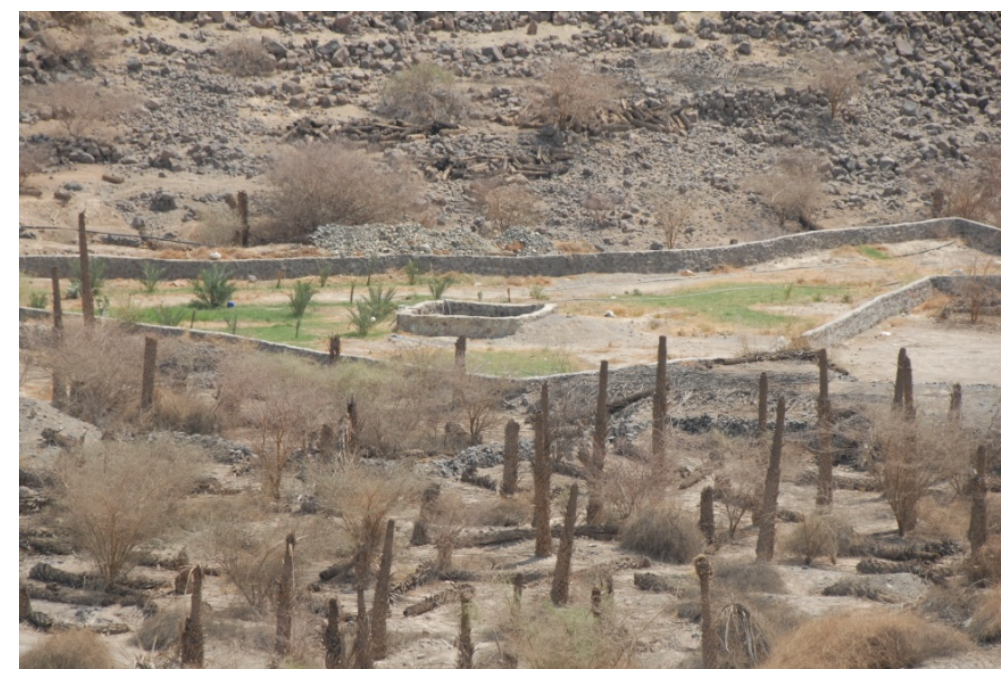

The wadi channels in which the villages and farms lie are moderate to low sloped features that contain alluvial sediments and are periodically flooded to variable degrees. A large number of large diameter wells are used to supply groundwater where it is still available. Many of the wells have been 
abandoned because of resource depletion or contamination with saline water and/or nitrates. Entire conventional treatment facilities have been abandoned (Figure 3). In areas where groundwater depletion has occurred, the only method of obtaining potable and irrigation water is to purchase it from suppliers and have it hauled by tank truck to fill onsite storage tanks. At Wadi Qidayd, the cost for treated water is $\$ 1.60-1.87 / \mathrm{m}^{3}$ and for untreated water $\$ 0.27-0.40 / \mathrm{m}^{3}$. The source of the truck-transported water is often local wells, the use of which contributes to further aquifer depletion. Use of the wadi aquifers for water supply at current rates is not sustainable. The lack of effective rainfall and associated recharge in the lower part of the Wadi Qidayd basin for the past several years has caused the shutdown of several local water suppliers due to dry wells.

Figure 2. Two-meter diameter well showing the water level at about $20 \mathrm{~m}$ below surface in Wadi Qidayd, western Saudi Arabia.

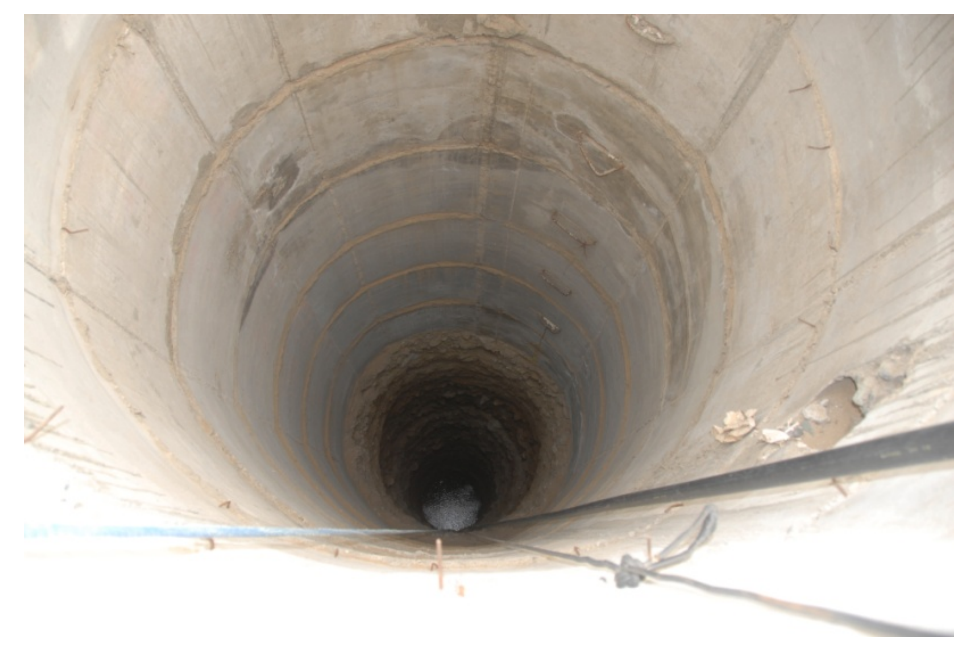

Figure 3. Abandoned municipal well that served a village water treatment facility.

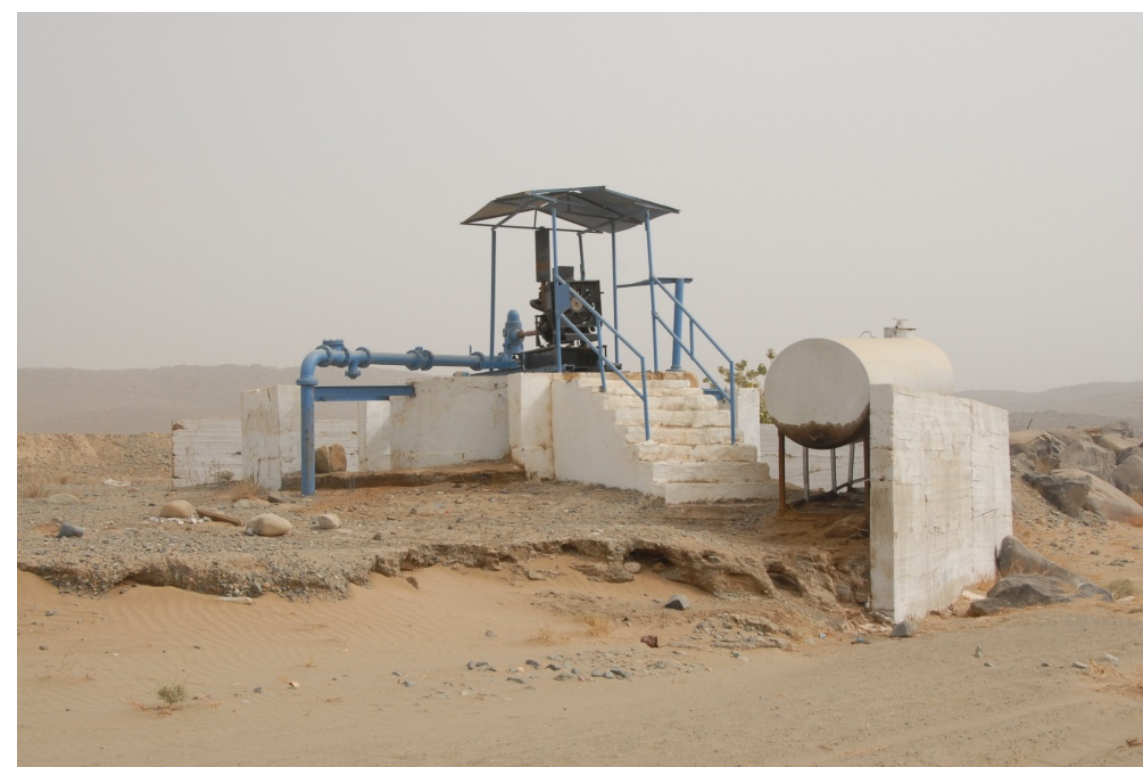




\subsection{Estimation of Wastewater Treatment Costs}

Wastewater treatment costs have been estimated from the literature for primarily conventional treatment technologies that will provide a relatively high degree of purity to allow indirect potable use. The technologies evaluated are discharge lagoons/oxidation ponds with natural infiltration (LAG), conventional trickling filters, conventional activated sludge (CAS) with nutrient removal (i.e., secondary treatment) as nitrates can adversely impact drinking water quality, assessing CAS as conventional aeration tanks or oxidation ditches (CAS-OxD), advanced treatment using an integrated membrane bioreactor system (MBR), and conventional activated sludge followed by tertiary filtration (CAS-TF). The final polishing of the treated domestic wastewater is assumed to be aquifer treatment, whereby the treated wastewater is placed into the alluvial aquifer using wells and the extraction for potable use is from wells located down-gradient. It is known that some refractory trace organic compounds will not be removed from the wastewater and further treatment may be required at extraction points closer to larger population centers. Although there are some public concerns regarding possible impacts of these compounds on human health, there are currently no drinking water standards established for them [7]. The available evidence suggests that exposure to trace concentrations of pharmaceuticals (at concentrations found in treated wastewater and water) is unlikely to cause health effects $[8,9]$.

Capital and operating costs for the various wastewater treatment technologies are comparatively developed, which are then systematically compared to seawater desalination costs.

\subsection{Estimation Methods for Desalination Costs}

Compilation and analysis of desalination costs have been published recently [10] based on past and recently collected cost data. The costs estimated for seawater desalination are focused on SWRO because it is the least costly of the large-scale desalination methods currently being used in the KSA and can be designed and constructed at a variety of capacities. Thermal desalination systems are quite difficult to design, construct, and operate at small capacities, especially in consideration of the rather small water use requirements in some wadi systems. Low-capacity, renewable-energy driven systems, such as solar stills cannot be used because of the lack of any local supply of water, saline or fresh.

SWRO costs are developed for a range of capacities. There is an economy of scale that generally causes larger-capacity SWRO systems to operate at lower costs compared to small capacities. However, many of the wadi communities are widely separated from large population centers and would require the development of comparatively low capacity SWRO systems. It would be less expensive to construct and operate a small scale SWRO plant to serve a number of small communities, than to pipe treated water a great distance from the very large-capacity desalination plants located near major population centers [11].

\subsection{Estimation of Conveyance Costs}

The cost of conveyance is based on design and construction of the pipelines using a standard diameter high-density polyethylene pipe (HDPE). The pipe would be buried primarily within the wadi channels at the proper location and depth to avoid damage during flow events. The burial depth is 
estimated to average $1 \mathrm{~m}$ below grade. The two pipe diameters considered are OD $1100 \mathrm{~mm}$ and OD $630 \mathrm{~mm}$. The strength grade of the HDPE pipe is 16 BAR PE 100. These large-diameter pipeline sizes are used with the assumption that there will be off-takers of water along the trunk lines and reduced diameter pipelines would serve the most distal farms and villages.

It is assumed that a pumping station will be required for each $40 \mathrm{~km}$ of pipeline. The average elevation change is estimated to be about $70 \mathrm{~m}$ and head losses due to pipe friction limit the overall head loss to no greater than $120 \mathrm{~m}$. Electrical requirements are estimated based on the friction head loss for the two pipe diameters plus the elevation head required.

Costs of the pipeline design and construction and the pumping stations are estimated based on conversations held with contractors in KSA (Jeddah city) and consulting engineers in the United States that have Middle East region experience. Engineering design and construction observation costs for the pipeline and pumping stations are estimated as about $15 \%$ of the total construction cost based on KSA practices.

\subsection{Estimation Methods for Treated Water by ARR/MAR Systems}

ARR/MAR costs are estimated based on the construction of both large $(2 \mathrm{~m})$ and smaller $(0.5 \mathrm{~m})$ wells using local drilling contractors. The injection of the water is designed to use the line pressure from the pipeline and is essentially either a gravity feed system or a low pressure injection system. The down-gradient recovery well pump costs and electrical use are based on an average lift of $25 \mathrm{~m}$ using electric turbine pumps. A few different pumping rates were used based on the well types and desired capacities.

It should be noted that there are hundreds (or thousands) of abandoned or seldom-used, large-diameter wells located throughout the wadis of western KSA. Wherever possible, existing wells would be used. In some cases, the wells would have to be rehabilitated or repaired. Also, these abandoned wells were commonly located adjacent to the villages and farms where the water would be used.

\subsection{Water Treatment}

Water recovered from the ARR/MAR treatment systems for potable use is of generally high quality. It is assumed that the only post-recovery treatment would be disinfection using chlorine.

Water from the system used for agricultural purposes would not be treated. Some farms may choose to install storage tanks to allow higher irrigation rates during the nighttime. This would ameliorate any supply and demand imbalances and would keep the pipeline costs lower (smaller diameter pipes).

Most houses and public buildings in the wadi communities are equipped with storage tanks, which would allow a lower amount of system common storage to be used for ARR/MAR recovered and treated water. Therefore, only relatively small capacity storage tanks are used for the village supply systems. Distribution piping system costs are not included in these estimates because of the large differences in demand for population centers ranging from a few families to perhaps 3000 people. Currently, many villages are not equipped with distribution systems, particularly the smaller population centers where water is trucked to the users. This practice may remain after system installation, but the quality of water would be truly potable. 


\section{Results and Discussion}

\subsection{Seawater Desalination Treatment Costs}

The KSA is the world's largest user of desalinated seawater, accounting for about $18 \%$ of the total global capacity [12]. The most used desalination technology in the KSA is multi-stage flash (MSF) distillation which is very energy intensive accounting for up to $70 \%$ of the desalination costs, and these plants are expensive to maintain [13]. In recent years, the KSA has begun to use large scale SWRO, but most commonly in hybrid facilities containing electric generation, MSF, and SWRO [14]. In addition, many standalone SWRO and brackish water reverse osmosis (BWRO) plants, with capacities ranging between $50 \mathrm{~m}^{3} / \mathrm{d}$ and $17,500 \mathrm{~m}^{3} / \mathrm{d}$, have been installed by the private sector [12]. On the other hand, multi-effect distillation (MED) is being used to replace the MSF process in other sites in the KSA, mainly with enhanced performance using thermal vapor compression (TVC) in a hybrid MED-TVC configuration (Table 1). It is difficult to ascertain the true cost of seawater desalination in the KSA because all utilities are subsidized by the government, and, commonly, freshwater is provided at vey low cost to the consumer [10]. Also, there are virtually no legal restrictions on water use and legal guidelines on reclaimed water use in the KSA.

Table 1. Water cost of different thermal desalination projects in Kingdom of Saudi Arabia (KSA), including subsidies (Global Water Intelligence/Water Desalination Report (GWI/WDR), 2009-2014).

\begin{tabular}{cccc}
\hline Site & $\begin{array}{c}\text { Capacity } \\
\left(\mathbf{m}^{\mathbf{3}} / \mathbf{d}\right)\end{array}$ & $\begin{array}{c}\text { Capital Cost } \\
(\mathbf{U S D})\end{array}$ & $\begin{array}{c}\text { Total Water Cost } \\
\left(\mathbf{\$} / \mathbf{m}^{\mathbf{3}}\right)\end{array}$ \\
\hline $\begin{array}{c}\text { Shoaiba MSF } \\
\text { Marafiq multi-effect distillation-thermal } \\
\text { vapor compression (MED-TVC) } \\
\text { Rabigh MED-TVC }\end{array}$ & 880,000 and $900 \mathrm{MW}$ & $\$ 2.4 \mathrm{~B}$ & 0.95 \\
& 800,000 & $\$ 3.4 \mathrm{~B}$ & 0.83 \\
\hline
\end{tabular}

Some water cost estimates can be made for the various seawater desalination facilities based upon energy consumption for the different technologies being used. These costs are truly scale dependent based on the capacity of the treatment facilities (e.g., large capacity facilities generally produce water at a generally lower unit cost compared to small facilities) [15] (Figure 4). Within the KSA, thermal desalination costs, including subsidies, range between $\$ 0.83$ and $\$ 1.5 / \mathrm{m}^{3}$ depending on the technology used, age of the facility, and the plant capacity. Hybrid water desalination facilities costs depend strongly on the hybrid configuration used along with the capacity. The total water cost produced by a MSF-SWRO hybrid system is $5 \%-10 \%$ less compared to MSF standalone plants [16]. On the other hand, SWRO facilities (standalone) produce freshwater at a cost ranging from $\$ 0.5$ to $\$ 1.5 / \mathrm{m}^{3}$, depending on several parameters, such as feed water salinity, requested product quality (includes post-treatment), and electrical energy, land and labors costs. Water cost of some thermal desalination plants in the KSA is presented in Table 1.

Another important factor affecting desalination water cost for rural communities is the distance of the end users from the coast or from large population centers that are served by high-capacity desalination facilities. In wadi communities located within a $50-100 \mathrm{~km}$ radius of a major desalination 
facility, the actual freshwater production cost would be the same as for the city residents, but the additional cost would be for transmission. In remote communities, the design, construction, and operation of standalone SWRO or BWRO facilities with a moderate to low capacity would likely be required and their costs might be very competitive with long water transfer from coastal desalination plants [11]. However, the feed water sources to supply these local plants within the wadi areas are not sustainable and therefore, would not be a reliable water supply. Overall desalination costs could be quite high from these facilities, located near the user (if possible) or at the shoreline, with a probable range from $\$ 1.25-5 / \mathrm{m}^{3}$.

Figure 4. Investment $\operatorname{cost} / \mathrm{m}^{3}$ for seawater reverse osmosis (SWRO) and brackish water reverse osmosis (BWRO) systems. Note the reduction as the capacity increases.

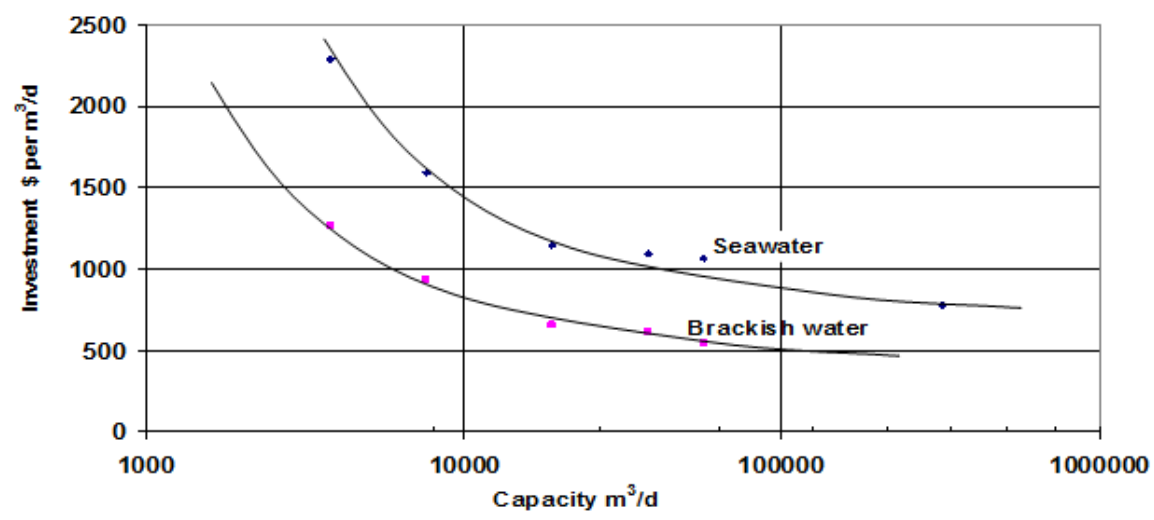

Installation of small-scale innovative desalination processes at the shoreline, powered with solar energy, may produce water at a lower cost and would require less maintenance and chemical use [17]. Low-energy processes, such as membrane distillation, could be the best solution for communities living in rural areas. Also, each village would be responsible for providing water storage and a distribution system where the population density permits doing so. Existing systems depend upon trucking water from a well (if available) and conveying the water to storage tanks located at each home or cluster of homes. This system also has a cost.

\subsection{Domestic Wastewater Treatment Costs}

Wastewater treatment plants naturally vary in capacity as a function of the community being serviced as well as the underlying infrastructure approach used (e.g., individual households versus decentralized/satellite designs and large centralized technologies). There is also an economy of scale that generally causes larger-capacity treatment plants to operate at lower costs compared to small capacity plants. For smaller communities (e.g., villages and farms) the operating costs for a treatment system will therefore fall in the higher range of cost estimates. In addition, the type of treatment technology selected will impact both capital and operating costs. A complicating factor in such an assessment is the difference in both regional and local parameters, such as land cost (i.e., impact of plant footprint), and the unit cost for energy.

In rural communities there is a tendency to choose low-technology solutions which typically require a lot of space (on the assumption that land costs are minimal) and which will require a minimum of skilled-labor maintenance. However, for a water reclamation and reuse strategy, there is a move to 
more advanced treatment systems to ensure reliable, safe, and high water quality as defined by the end use. In this cost estimate, representative treatment technologies, which can be defined as low to high technology solutions, have been included in the comparison. These include ponds and lagoons, trickling filters, variations of conventional activated sludge (CAS) (e.g., secondary treatment/oxidation ditches), tertiary treatment of secondary effluent (e.g., membrane filtration/advanced oxidation), and membrane bioreactor technology (MBR) as an alternative advanced tertiary treatment system. A direct comparison of capital costs for these technologies is not straight forward, although studies in the literature can be found showing that high technology options are cost competitive to low technology alternatives [18-21].

In most studies assessing operating costs for various treatment technologies, energy is highlighted as a key parameter for defining the operating costs, typically in the range of $40 \%-60 \%$ of total costs $[18,19]$. The specific energy consumption for wastewater treatment is reported in the range of $0.4-1.0 \mathrm{kWh} / \mathrm{m}^{3}$ of treated water $[19,21,22]$. Breaking this down to commonly used technologies in terms of sophistication of the treatment plant gives the ranges or $0.08-0.28 \mathrm{kWh} / \mathrm{m}^{3}$ for lagoons, $0.19-0.41 \mathrm{kWh} / \mathrm{m}^{3}$ for trickling filter plants, $0.33-0.61 \mathrm{kWh} / \mathrm{m}^{3}$ for conventional activated sludge, and $0.48-1.03 \mathrm{kWh} / \mathrm{m}^{3}$ for oxidation ditches and tertiary treatment. Membrane bioreactors are perceived as being energy intensive, however recent case studies comparing average energy requirements for tertiary treatment based on conventional activated sludge compared to MBR have shown that a relatively large MBR plant consumes $0.9 \mathrm{kWh} / \mathrm{m}^{3}$ compared to a range of $0.5-1.8 \mathrm{kWh} / \mathrm{m}^{3}$ for the tertiary conventional activated sludge options [18,20,23-28]. On the assumption that energy costs on average are $50 \%$ of the total operating costs, energy can be estimated at $0.01-0.210 / \mathrm{kWh} / \mathrm{m}^{3}$, an estimate for a lower and upper range of operating costs for various wastewater treatment technologies can be compared. The results are shown in Figure 5.

Figure 5. Estimated $\operatorname{cost} / \mathrm{m}^{3}$ for wastewater treatment using different technologies.

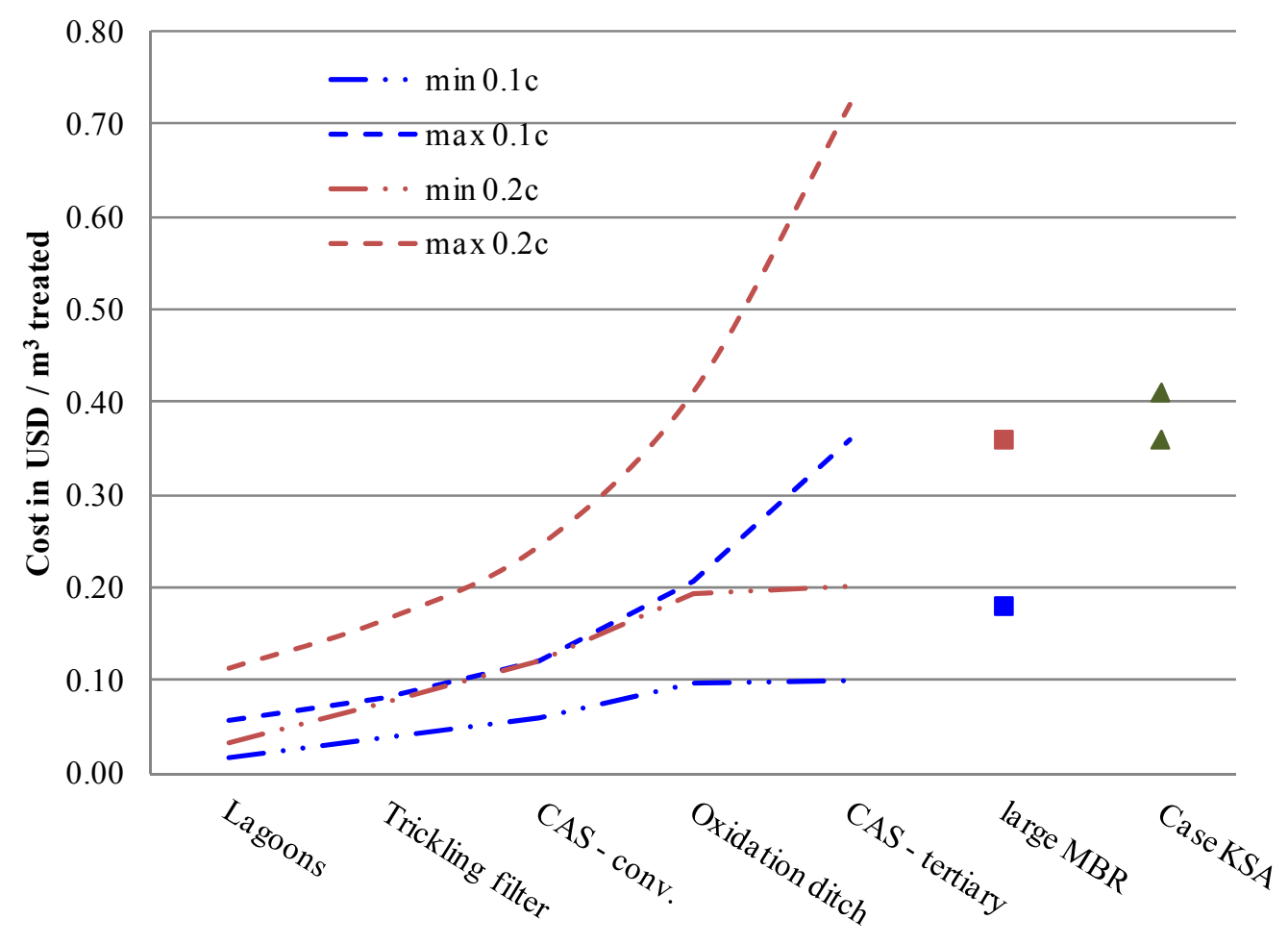


For the low technology options (e.g., lagoons, trickling filters) the treatment costs will range between $\$ 0.05-0.20 / \mathrm{m}^{3}$ depending on the criteria chosen, however, it is debatable whether the water quality achieved is well suited for reuse. Conventional activated sludge is a more appropriate technology with respect to treated water quality and design options resulting in costs ranging between $\$ 0.10-0.50 / \mathrm{m}^{3}$. It is interesting to note that conventional activated sludge designed as an oxidation ditch can be relatively higher in O\&M costs, as exemplified by the example of case studies in the KSA [26,27]. Treatment of wastewater to a high quality suitable for reuse can be achieved by conventional activated sludge followed by advanced tertiary treatment, estimated at a cost ranging from $\$ 0.10-0.70 / \mathrm{m}^{3}$ based on a series of assumptions. For this level of treatment, MBR technology is shown to be more efficient with estimated costs of less than $\$ 0.40 / \mathrm{m}^{3}$ [23,24]. In recent research conducted on advanced treatment of wastewater by MBR technology, it was shown to be very competitive an as alternative to desalination options [23,24]. With respect to rural populations having to rely on desalination as a reliable water source, it is apparent for the simple estimations shown above that advanced treatment of wastewater for both non-potable and indirect-potable reuse is a viable and sustainable option.

\subsection{Conveyance Cost}

The cost to convey water from the treatment plant to the end user is quite significant, especially in the isolated rural environment. Conveyance cost can be broken down into capital and operating costs. Capital costs include the pipeline engineering and construction, the cost of the pumping stations, and some undefined costs of conveyance, such as construction of pipelines crossing roads and municipal infrastructure at large facilities. The operating costs include the electrical costs and are mostly for electricity to run the pumps. Any additional costs associated with the operation of ASR wells are considered to be minor within the overall assessment.

Wadi valley pipeline engineering design and construction are relatively simple, but require consideration of periodic flooding within the wadi channels and potential erosion of the main channel area. The soils are predominantly sands and gravels and are easy to excavate. The preferred pipeline material can be HDPE. The strength of the pipe should be 16 BAR PE 100 to prevent any damage due to movement during earthquakes and by trucks or other farm equipment. The cost for materials and installation of HDPE pipe in the wadi valleys of Saudi Arabia is given in Table 2. The hydraulic gradient from the shoreline to the heads of the wadi valleys is not very steep and the overall elevation rise is likely not more than $70 \mathrm{~m}$ over a distance of about $40 \mathrm{~km}$. Pumping station costs were obtained for a variety of facilities ranging in capacity from 5000 to $40,000 \mathrm{~m}^{3} / \mathrm{d}$. The cost for such facilities in western Saudi Arabia is roughly $\$ 500,000 / 5000 \mathrm{~m}^{3} /$ day of capacity (Table 2). A preliminary assessment shows that a single pumping station can be used to transmit this range of capacities between 40 and $60 \mathrm{~km}$, assuming that the overall head loss is no greater than $120 \mathrm{~m}$.

Only two relatively large diameter pipe sizes are listed in the table. Since wadi systems contain a series of local farms and village occurring along a linear geometry or with a series of branches, these pipeline diameters would be used as trunk lines and could be reduced in diameter from proximal to distal users. For cost estimation purposes, the larger diameters should be used because the cost of construction will likely be nearly the same for the next lower set of pipe diameters. 
The electrical use for operation of the pumping stations to convey the water from the source to the use area is dependent on the required capacity (Table 2). The kilowatt-hours of electricity per day are also given in Table 2. The subsidies used in Saudi Arabia make the determination of real electric costs quite difficult to estimate, but the real cost likely ranges from $\$ 0.05-0.15 / \mathrm{kw}-\mathrm{h}$. An estimated cost range to convey the water $40 \mathrm{~km}$ is $\$ 0.45-1.50 / \mathrm{m}^{3}$.

Since the key aspect of this research is the comparison of costs between use of desalinated water and reuse of highly treated domestic wastewater indirectly via an MAR system for potable supply and directly for irrigation use, the cost of conveyance of the water will be the same for either option. It can be calculated from the data given in the tables. If the water is conveyed from great distance, the cost of desalinated water delivery will be roughly doubled. The multiplier will be even greater for conveyance of highly treated wastewater because of its lower treatment cost.

Table 2. Estimated cost for construction of high-density polyethylene pipe (HDPE) pipelines in wadi systems.

\begin{tabular}{lll}
\hline Cost Item & Cost $/ \mathbf{k m}$ & \\
\hline $1100 \mathrm{~mm}$ outside diameter HDPE pipe (rated 16 Bar PE 100) & $\$ 7,000$ & \\
630 mm outside diameter HDPE pipe (rated 16 Bar PE 100) & $\$ 3,000$ \\
Construction cost (wadi sediments, 1 m burial depth, with fittings) & \\
For 1100 mm pipe & $\$ 107,000$ \\
Construction cost (wadi sediments, 1 m burial depth, with fittings) & & \\
For 1100 mm pipe & $\$ 80,000$ & \\
HDPE Pipeline Diameter (rated 16 Bar PE 100) & Cost/km Total ${ }^{1}$ \\
$1100 \mathrm{~mm}$ outside diameter & $\$ 114,000$ & \\
$630 \mathrm{~mm}$ outside diameter & $\$ 83,000$ & \\
Pumping Station ( $\mathrm{m}^{3} /$ day) (total head required =100 m) & CAPEX & OPEX (kw-h/day) \\
5,000 & $\$ 500,000$ & 38,000 \\
10,000 & $\$ 1,000,000$ & 76,000 \\
20,000 & $\$ 2,000,000$ & 152,000 \\
30,000 & $\$ 3,000,000$ & 228,000 \\
40,000 & $\$ 4,000,000$ & 304,000 \\
\hline
\end{tabular}

Notes: ${ }^{1}$ The assumed total dynamic head is estimated to be $122 \mathrm{~m}^{2}$ Real cost of electric power in the KSA is estimated to range from $\$ 0.05-0.15 / \mathrm{kw}-\mathrm{h}$.

\subsection{Cultural and Religious Issues Involving Wastewater Reuse}

A major challenge for indirect potable reuse projects is obtaining public acceptance. Public perception issues associated with reuse of reclaimed water were reviewed by Maliva and Missimer [2]. In general, public acceptance of the reuse of reclaimed water increases with increasing "distance" or isolation from the treated wastewater. There is generally a high level of acceptance for projects with no human exposure and a much lesser support for projects with direct human contact.

The passage of water through a natural environment, such as an aquifer, also reduces its "taint" of being wastewater. Public acceptance also depends upon the recognition by the effected population of the severity of the water shortage and confidence in the agency or organization that will implement the project. Reuse of reclaimed water and even indirect potable reuse are not contrary to Islamic Law. The 
Council of Leading Islamic Scholars in Saudi Arabia issued a fatwa in 1978, stating that reclaimed water can be used for ablution and drinking if it is sufficiently and appropriately treated to ensure good health, but recommended avoiding use of treated wastewater for drinking purposes to avoid health problems and also in consideration of the negative public sentiment about this water. If drinking is to be avoided, it is to be merely for reasons of public health and safety, not due to any ramifications of Islamic Law [29].

Wastewater is already being recharged to some wadi alluvial aquifers downstream of wastewater treatment plants and through on-site disposal systems, so the introduction of the more controlled upgraded wastewater treatment/ARR could, in some instances would, result in improved water quality. Nevertheless, obtaining local public support will be a critical feasibility issue, which will need to start with a public education campaign. A lack of knowledge on issues such as wastewater quality, health risks, and for farmers, impacts on soils and crops often leads to a negative perception of wastewater reuse.

\subsection{Cost for ARR (MAR) Construction and Operation}

In most cases, the number of abandoned, large-diameter wells would be sufficient to meet the need for existing small villages and farms, at least for the upgradient injection well or wells for each site. At locations where an additional well is required to recover the injected water, the construction cost for a well ranges from $\$ 5000$ to 20,000 depending on the depth and diameter of the well. The recovery pump would be a diesel-powered vertical turbine pump with a head lift maximum of $50 \mathrm{~m}$. Typical pumps used in the wadi systems cost about $\$ 7500$. The cost of fuel to power the pumps is subsidized and is about $\$ 0.25 / \mathrm{L}$. Therefore, the operational cost of a small ARR system for a village is $<\$ 0.05 / \mathrm{m}^{3}$. The treatment cost and conveyance of the source water is greater than this cost.

\subsection{Indirect Reuse and Irrigation Use Using MAR Treatment of Domestic Wastewater for Wadi}

\section{Communities in the KSA: Special Circumstances}

The economic analyses developed in this research suggest that the use of treated domestic wastewater combined with ARR polishing for indirect potable use is the most economical solution to meet the rural water supply requirements, but it is still costly. However, there are extenuating circumstances that greatly affect the economics of water reuse which include the current practice of disposal of the treated or untreated wastewater and its adverse environmental effects on the marine environment and some inland aquifer water quality.

Only about $10 \%$ of the wastewater generated in the KSA is reused in a beneficial manner. Partial treatment and discharge to tidal water or into channels transmitting into the desert with no users are not economically beneficial. Therefore, a real cost comparison between use of desalinated water and wastewater should consider that there is zero cost for treatment of the wastewater if it is being discharged to waste. In fact, environmental damage caused by inappropriate wastewater disposal practices produces a negative economic impact, which must be considered in this analysis.

Wastewater discharges to tide adversely affect the fringing reef of the Red Sea as occurs in all coral reef ecosystems [30-32], which in turn, adversely affects fisheries and the potential recreational aspects of the reef ecosystem. Coral reef ecosystems provide a diverse variety of goods and services to 
humanity [33,34]. Goods and services of all natural systems of the Earth affect the human economy and well-being [35]. Anthropogenic impacts on coral reefs have a direct economic impact on the recreational value of reefs that can be measured [36]. Economic assessments by Cesar [37] and Berg et al. [38] found that losses to coral reef tourism caused by the destruction of $1 \mathrm{~km}^{2}$ of reef ranged between $\$ 27,900$ and $\$ 100,800$ USD and \$5500 and \$368,000 USD, respectively. A loss of $\$ 40$ million USD over a 10-year period was estimated by Hodgson and Dixon [39] for tourism and fisheries declines in a coastal area of the Philippines. While the Red Sea of KSA does not have a well-developed ecotourism industry, it is greatly dependent on the fisheries, which may generate an event larger overall economic impact.

There is a negative cost impact on the disposal of each $1 \mathrm{~m}^{3}$ of wastewater discharged to tidal water in the vicinity of a coral reef system. This cost depends on the concentration of nutrients within the wastewater, the degree of treatment for removal of solids and organic carbon, the proximity of the discharge to the reef, and the nearshore current patterns. A crude estimate of this cost range is $\$ 0.05-0.20 \mathrm{USD} / \mathrm{m}^{3}$ for the economic losses associated with marine pollution. The range of loss associated with discharge to wadi aquifers and contamination of groundwater cannot really be estimated for areas where there is no significant water use.

\subsection{Long-Term Sustainability of Seawater Desalination to Meet Rural Water Demands: Subsidies}

In any economic analysis, the issue of sustainability must be raised within the context of the water supply options being assessed. Based on the economic return of the relatively small population and the farms within the wadi valleys, the cost of supplying desalinated seawater to these areas would have to be subsidized by the government to bring economic viability to the residents and farmers. This issue raises questions concerning the long-term viability of a fully subsidized water supply within the context of the Saudi Arabian economy. However, there may be some mitigating economic issues with regard to food security which cannot be evaluated within the context of this research.

Electricity, fuel, and utilities are all nearly fully subsidized in KSA. The root of economic prosperity in the KSA is the income received from the international sale of petroleum [40]. In 2009, $25 \%$ of the petroleum produced in the KSA was consumed domestically and with population growth, this percentage will likely continue to rise [41]. This means that as domestic petroleum consumption rises, the petroleum available for export sale declines, and overall revenue income will decline with time. Also, the rate of domestic energy consumption in the KSA is greater than the United States. Declining revenue raises the question whether significant water use that provides little or no economic return can be maintained.

All other subsidies, including water supply and wastewater treatment are also subsidized to a nearly full degree. However, water and wastewater tariffs are being assessed to a limited degree in an attempt to recover some costs of providing utility service to the public and industry. There has been considerable push-back by the general population and industry that have grown comfortable with free utility services. Ramady [40] suggests that continuation of subsidies is a great challenge that is part of greater economic reform, which will be required in the future. Krane [41] has suggested that most economists believe that continued maintenance of utility subsidies threatens the stability of the Saudi Arabian economy. Therefore, the long-term economic sustainability of providing desalinated water to 
small villages and farms for drinking and irrigation water is debatable and questionable. This suggests that choosing the low cost water supply alternative, despite religious and cultural questions, may be the only viable long-term water supply option.

\section{Conclusions}

There are limited options to supply water to the rural villages and farms located in western Saudi Arabia as well as other such communities located in similar global arid lands areas. A comparison of actual treatment costs between providing desalinated seawater for potable and irrigation uses to use of highly treated domestic wastewater with MAR polishing show a difference of nearly $300 \%$. The overall cost of SWRO treatment with conveyance of the water over a distance of $40 \mathrm{~km}$ ranges from $\$ 1.70-6.50 / \mathrm{m}^{3}$. Treatment cost of domestic wastewater ranges from $\$ 0.10-0.80 / \mathrm{m}^{3}$. Conveyance cost for a distance of $40 \mathrm{~km}$ ranges from $\$ 0.45-1.50 / \mathrm{m}^{3}$. The use of local ARR systems using existing wells and a new well with a new pump is about $\$ 0.05 / \mathrm{m}^{3}$. Therefore, the water reuse system including treatment, conveyance and the ARR final treatment and operation ranges from $\$ 0.6-2.35 / \mathrm{m}^{3}$. If it is assumed that the treatment cost of the wastewater is zero, because it is currently not used or is discharged to waste, then the cost range declines to $\$ 0.5-1.55 / \mathrm{m}^{3}$.

The costs developed herein are rather specific to the western Saudi Arabia region, but can be estimated for any region based on the cost per kw-h for power consumption and correction for local electric rates. Construction costs vary greatly worldwide, but when these costs are amortized over a period of 20 years or greater, the impact on the cost per cubic meter to the consumer is minimal. This is particularly evident in regions where long conveyance of any source water is required.

Use of MAR for storage and polishing treatment of highly treated domestic wastewater is a significant method to minimize cost to supply safe drinking and irrigation water to rural areas in arid lands. Such systems need to be explored for use in areas where wastewater is being discharged with no economic benefit and alternative sources of water are extremely expensive.

\section{Acknowledgments}

Funding for this research was provided by the Water Desalination and Reuse Center at the King Abdullah University of Science and Technology and from discretionary faculty funding from the same university. We thank Mohammed Saud, Vice President, Moya Bushnak Water and Environmental Services Company, Jeddah, Saudi Arabia for providing construction cost estimates. We also thank Thomas Burke, Chief Engineer of the Southwest Florida Water Management District for information on pumping station capital and operating costs.

\section{Authors Contributions}

Thomas Missimer was the lead author and contributed the text including the introduction, the text on MAR/ARR, conveyance cost, and the special circumstances that impact wastewater reuse costs. Robert Maliva contributed the text on public acceptance of treated wastewater reuse and some of the MAR/ARR text. Noreddine Ghaffour contributed the economics of seawater desalination. TorOve Leiknes contributed the economics of wastewater treatment as applied to arid lands and reuse. Gary 
Amy provided some of the wastewater reuse text and edited the overall paper based on his wastewater reuse experience.

\section{Conflicts of Interest}

The authors declare no conflict of interest.

\section{References}

1. Missimer, T.M.; Drewes, J.; Amy, G.L.; Maliva, R.G.; Keller, S. Restoration of wadi aquifers by artificial recharge with treated wastewater. Groundwater 2012, 50, 514-527.

2. Maliva, R.G.; Missimer, T.M. Arid Lands Water Evaluation and Management; Springer: Heidelberg, Germany, 2012.

3. Hussein, M.T.; Bazuhair, A.; Thabet Al-Yamani, M.S. Groundwater availability in the Khulais Plain, western Saudi Arabia. Hydrol. Sci. J. 1993, 38, 203-213.

4. El Kharraz, J.; El-Sadek, A.; Ghaffour, N.; Mino, E. Water scarcity and drought in WANA countries. Procedia Eng. 2012, 33, 14-29.

5. Lopez, O.; Stenchikov, G.; Missimer, T.M. Climate change water management using aquifer storage and recovery of stormwater. Environ. Res. Lett. 2014, in press.

6. Lawrence, T.E. Seven Pillars of Wisdom; Oxford Press: Oxford, UK, 1922.

7. Daughton, C.G.; Ternes, T.A. Pharmaceuticals and personal care products in the environment: Agents of subtle change? Environ. Health Perspect. 1999, 107, 907-938.

8. American Water Works Association Research Foundation. Toxicological Relevance of EDCs and Pharmaceuticals in Drinking Water; American Water Works Research Foundation: Denver, CO, USA, 2008.

9. Watts, C.; Maycock, D.; Crane, M.; Fawell, J. Desk Based Review of Current Knowledge on Pharmaceuticals in Drinking Water and Estimation of Potential Levels; Water Desalination Report; Water Desalination Report: London, UK, 2013.

10. Ghaffour, N.; Missimer, T.M.; Amy, G.L. Technical review and evaluation of the economics of water desalination: Current and future challenges for better water sustainability. Desalination 2013, 309, 197-207.

11. Quteishat, K. Desalination and water affordability. In Proceedings of the SITeau International Conference, Casablanca, Morocco, January 2009.

12. Global Water Intelligence (GWI/IDA DesalData), Market Profile and Desalination Markets, 2009-2014 Yearbooks and GWI. Available online: http://www.desaldata.com/ (accessed on 15 April 2014).

13. Ghaffour, N. The challenge of capacity building strategies and perspectives for desalination for sustainable water use in MENA. Desalin. Water Treat. 2009, 5, 48-53.

14. Al-Osaimi, M. Shoaiba thermal and membrane desalination process comparison. In Proceedings of the KAUST Thermal Desalination Workshop, Thuwal, Saudi Arabia, 12-13 March 2013.

15. Maurel, A. Seawater/Brackish Water Desalination and Other Non-Conventional Processes for Water Supply, 2nd ed.; Lavoisier: France, 2006; ISBN: 10:2-7430-0890-3. 
16. Awerbuch, L. Hybridization and dual purpose plant cost considerations. In Proceedings of the MEDRC International Conference on Desalination Costing, Conference Proceeding, Lemesos, Cyprus, 6-8 December 2004.

17. Ghaffour, N.; Lattemann, S.; Missimer, T.M.; Ng, K.C.; Sinha, S.; Amy, G. Renewable energy-driven innovative energy-efficient desalination technologies. Appl. Energy 2014, doi:10.1016/j.apenergy.2014.03.033.

18. Brepols, C. Operating Large Scale Membrane Bioreactors for Municipal Wastewater Treatment; IWA Publishing: London, UK, 2011; ISBN: 9781843393054.

19. Water-Energy Interactions in Water Reuse; Lazarova, V., Choo, K.-H., Cornel, P., Eds.; IWA Publishing: London, UK, 2012; ISBN: 9781843395416.

20. Bixio, D.; Thoeye, C.; de Koning, J.; Joksimovic, D.; Savic, D.; Wintgens, T.; Melin, T. Wastewater reuse in Europe. Desalination 2006, 187, 89-101.

21. Green Drop Handbook; South African Wastewater Services, Department of Water Affairs: South Africa, 2013.

22. WaterWorld. Survey Examines Wastewater Treatment Costs. Available online: http://www.waterworld.com/articles/iww/print/volume-11/iss (accessed on 10 May 2014).

23. Cote, P.; Masini, M.; Mourato, D. Comparison of membrane options for water reuse and reclamation. Desalination 2004, 167, 1-11.

24. Cote, P.; Siverns, S.; Monti, S. Comparison of membrane-based solutions for water reclamation and desalination. Desalination 2005, 182, 251-257.

25. Bodik, I.; Kubaska, M. Energy and Sustainability of Operation of a Wastewater Treatment Plant. Environ. Prot. Eng. 2013, 39, 15-24.

26. Zahid, W.M. Wastewater Treatment Technologies for Water Reuse in Saudi Arabia. In Proceedings of the 2nd Saudi International Water Technology Conference 2014, King Abdulaziz City for Science and Technology (KACST), Riyadh, Kingdom of Saudi Arabia, 23-25 February 2014.

27. AlGhusain, I. The Sulaibiya Wastewater Treatment and Reclamation Plant. In Proceedings of the 6th Zayed Seminar, Green Economy, Manama, Bahrain, 8-9 May 2013.

28. Singhirunnusorn, W.; Stenstrom, M.K. A Critical Analysis of Economic Factors for Diverse Wastewater Treatment processes: Case studies in Thailand. Sustain. Environ. Resour. 2010, 20, 263-268.

29. Maliva, R.G.; Herrmann, R.; Winslow, F.; Missimer, T.M. Aquifer storage and recovery of treated sewage effluent in the Middle East. Arab. J. Sci. Eng. 2011, 36, 63-74.

30. Kinsey, D.W.; Davies, P.J. Effects of elevated nitrogen and phosphorus on coral reef growth. Limnol. Oceanogr. 1979, 24, 935-940.

31. Marubini, F.; Davies, P.S. Nitrate increase zooxanthellae population density and reduces skeletogenesis in corals. Mar. Biol. 1996, 127, 319-328.

32. Reopanichkul, P.; Schlacher, T.A.; Carter, R.W.; Worachananant, S. Sewage impacts coral reefs at multiple levels of ecological organization. Mar. Pollut. Bull. 2009, 58, 1356-1362.

33. Spurgeon, J.P.G. The economic valuation of coral reefs. Mar. Pollut. Bull. 1992, 24, 529-536.

34. Moberg, F.; Folke, C. Ecological goods and services of coral reef ecosystems. Ecol. Econ. 1999, 29, 215-233. 
35. Daily, G.C. Nature's Services: Societal Dependence on Natural Ecosystems; Island Press: Washington, DC, USA, 1997.

36. Wielgus, J.; Chadwick-Furman, N.E.; Dubinsky, Z.; Shechter, M.; Zeitouni, N. Dose-response modeling of recreationally important coral-reef attributes: A review and potential application to the economic valuation of damage. Coral Reefs 2002, 21, 253-259.

37. Cesar, H. Coral reefs: Their functions, threats and economic value. In Collected Essays on the Economics of Coral Reefs; Ceasr, H., Ed.; CORDIO/SIDA: Kalmar, Sweden, 2000; pp. 14-39.

38. Berg, H.; Ohman, W.H.; Troeng, S.; Linden, O. Environmental economics of coral-reef destruction in Sri Lanka. AMBIO 1998, 27, 627-634.

39. Hodgeson, G.; Dixon, J.A. Logging versus Tourism in Palawan: An Environmental and Economic Analysis; East-West Environmental and Policy Institute Occasional Paper no. 7; East-West Center: Honolulu, Hawaii, 1988.

40. Ramady, M.A. The Saudi Arabian Economy: Policies, Achievements, and Challenges, 2nd ed.; Springer: New York, NY, USA, 2010.

41. Krane, J. Stability versus Sustainability: Energy Policy in the Gulf Monarchies; Electricity Research Group Working Paper 1302 and Cambridge Working Paper in Economics 1304; University of Cambridge: Cambridge, UK, 2013.

(C) 2014 by the authors; licensee MDPI, Basel, Switzerland. This article is an open access article distributed under the terms and conditions of the Creative Commons Attribution license (http://creativecommons.org/licenses/by/3.0/). 